\title{
O ALEGRE CANTO DA PERDIZ, DE PAULINA CHIZIANE, E 0 RECONHECIMENTO DE ALGUNS ASPECTOS HISTÓRICO-CULTURAIS \\ MOÇAMBICANOS
}

\author{
O ALEGRE CANTO DA PERDIZ, BY PAULINA CHIZIANE, AND THE \\ RECOGNITION OF SOME MOZAMBICAN HISTORICAL-CULTURAL
}

ASPECTS

Mariany Teresinha Ricardo ${ }^{1}$

\begin{abstract}
Resumo: Este artigo se dedica à abordagem que o romance $O$ alegre canto da perdiz, escrito por Paulina Chiziane, confere à temática racial em Moçambique. Para tanto, a escrita do romance será situada dentro do contexto moçambicano, para, então, observarmos os impactos que o contato racial tem na formação identitária dos personagens. Esses impactos, por sua vez, estão relacionados aos processos de racialização e de diferenciação negativa vinculados aos processos de colonização e imperialismo europeus.
\end{abstract}

\begin{abstract}
This article is dedicated to the approach that the romance $O$ alegre canto da perdiz, written by Paulina Chiziane, confers to the racial theme in Mozambique. To do so, the written of the romance will be situated within the Mozambican context. Next, we will observe the impacts that the racial contact has on the identity formation of the characters. These impacts, in turn, are related to the processes of racialization and negative linked to the processes of European colonization and imperialism.
\end{abstract}

Palavras-chave: O alegre canto da perdiz; Paulina Chiziane; Raça; Diferenciação; Identidade.

Keywords: O alegre canto da perdiz; Paulina Chiziane; Race; Differentiation; Identity.

\section{Uma porta de entrada}

O quão (in)seguro pode ser estar vivo e querer contar sua história, a história de seu povo, a partir de um lugar que, muitas vezes, não é reconhecido enquanto espaço válido de construção de conhecimentos e saberes? O que pode haver de errado em reconhecer a existência de diferentes pontos de vista, credos e espaços de constituição de sujeitos? Conectado a esses questionamentos está, por sua vez, o pensamento que surge após o período colonial, no qual os valores que sustentaram a

$\overline{1}$ Mestranda em Literatura, com pesquisa intitulada Literaturas e relações culturais em um lugar ao Sul: diálogos com a escrita de Paulina Chiziane. Bolsista do CNPq.

Revista Crioula - n 24 - Dissidências de Gênero e Sexualidade nas Literaturas de Língua Portuguesa

$2^{\circ}$ Semestre 2019 
modernidade colonial passam a ser questionados de forma mais abrangente. Nesse viés se localiza, por exemplo, a perspectiva da existência de um Sul global (SANTOS, 2007), espaço marcado por desigualdades e confrontos, mas, também, por lutas empreendidas a fim de desafiar os discursos e as práticas sociais construídos dentro de uma ordem eurocêntrica², a fim de que seja direcionado o devido cuidado para com os processos de diferenciação e desigualdade que marcam a história do mundo, visando à (re)construção de uma sociedade global que acolha diferentes epistemologias³.

Nesse sentido, as literaturas escritas nos países africanos têm um lugar bastante importante, pois permitem com que sejam tecidas narrativas sobre sociedades que, por muito tempo, foram narradas por quem as colonizou. Entre essas narrativas, que operam em conjunto com trabalhos de pesquisadores como Said (1990) e Mudimbe (2013), os quais discutem a formação da alteridade pelo discurso colonial ${ }^{4}$, está aquela a ser analisada neste trabalho: O alegre canto da perdiz (2008), de autoria de Paulina Chiziane (1955-). Escrita após Paulina viver e trabalhar na província da Zambézia, em Moçambique, a narrativa comporta um cenário diferente (o Norte) daquele em que a escritora cresceu (o Sul), o qual, para além da forte influência da colonização portuguesa, conta com a presença do matriarcado ${ }^{5}$, de forma mais intensa que no Sul, da cultura islâmica ${ }^{6}$.

Além disso, é nessa região que houve maior miscigenação ao longo do processo de colonização portuguesa, o que está relacionado a questões como o investimento dos portugueses na ocupação desse território, em termos de um maior entrosamento com as populações locais, tendo em vista o estabelecimento de laços sociais que facilitassem também o alcance ao ouro. Situam-se, nessa perspectiva, "estratégias de sobrevivência dos aventureiros portugueses e 'indo-portugueses' que ali se estabeleceram." (CABAÇO, 2007)ㄱ, bem como o início do arrendamento de prazos pela Coroa Portuguesa no século XVII, cuja concessão de terras se dava preferencialmente às mulheres, a fim de atrair colonos para o casamento (CAPELA, 2005).

É, pois, diante desses elementos, que a narrativa se situa, ao explorar um universo em que, conforme será apontado no decorrer da discussão, as pessoas precisaram abdicar muito de si para atender às normas de um projeto civilizacional. Projeto este que serviu, dentre outras coisas, à infe$2 \quad$ Nesse viés, Andreas Huyssen (1942-), em "Mapeando o pós-moderno", menciona o movimento de mulheres, a emergência de discussões ecológicas e do meio ambiente e, citando Paul Ricouer, a crescente consciência sobre se relacionar com outras culturas de forma não dominante e conquistadora, como importantes lugares de resistência a práticas hegemônicas de modernização (HUYSSEN, 1992, p. 78-79).

3 No sentido do que Boaventura de Sousa Santos denomina, no artigo "Para além do pensamento abissal" (2007), de ecologia de saberes. $4 \quad$ Pensando o Oriente e o continente africano, respectivamente.

5 A opção pela palavra, nesse contexto, se dá por sua presença em $O$ alegre canto da perdiz. No entanto, estudos antropológicos apontam que o que há, nessa região de Moçambique, se trata da matrilineariedade, estrutura que faz parte da organização social de povos como os macondes e os macuas. (DIAS, 1964 apud MARCELINO, 2016, p. 20-21; MARTINEZ, 1989 apud MARCELINO, 2016, p. 21; PINTO, 2015)

6 Resumidamente, essa presença mais marcante está relacionada ao histórico da influência islâmica na região, tanto em termos comerciais quanto culturais, que levaram à organização de sociedades e ao estabelecimento de relações que ofereceram forte resistência à dominação portuguesa na região, tendo em vista aspectos como a preservação da autonomia política dessas mesmas sociedades. (MATTOS, 2004)

7 Cabaço (2007) registra que Afonso de Albuquerque (1452-1515), militar português que foi o segundo governador da Índia Portuguesa, "procuraria fazer suceder ao terror da conquista uma política de coexistência, incentivando casamentos entre expedicionários e mulheres locais." (CABAÇO, 2007, p. 129) 
riorização embasada na ideia de diferença de cor, que implicou na racialização das pessoas.

\section{Lugares da narrativa: a escrita de 0 alegre canto da perdiz e alguns dos conflitos identitá- rios e formativos em Moçambique}

Mesmo ocupando espaços significativos dentro da história de Moçambique, como a participação na luta pela independência, ser considerada a primeira mulher moçambicana a publicar um romance, em 1990 - em seguimento aos trabalhos de escrita feito por outras mulheres moçambicanas, como Noémia de Sousa (1926-2002), Lília Momplé (1935-) e Lina Magaia (1945-2011) - e ter recebido o título de embaixadora de paz pela África, em 2010, Paulina Chiziane (Manjacaze, 1955-) passou por uma série de percalços no decorrer de sua carreira, sendo incompreendida dentro de seu país. Em entrevista ao jornal $O$ País, ela menciona que tinha que "escrever de acordo com as mil autoridades que o país tem" e questiona: "É a igreja, a política ou as pessoas, tenho de as escrever bonitas por quê?" (CHIZIANE, 2016).

Esse questionamento, por sua vez, pode ser tomado enquanto indício de que há algo que não se valoriza ou reconhece e que se deseja ver apagado ou camuflado - em síntese, sem necessidade de valoração, lembranças ruins ${ }^{8}$. No entanto, a escritora insiste por permanecer nesse território de desafio ao que as autoridades desejam para o país, com o objetivo de descolonizar a mente dos próprios moçambicanos (CHIZIANE, 2014). Nesse viés, uma das características de suas obras se refere à presença de valores e ações que dizem respeito a práticas moçambicanas que não fazem parte dos valores europeus, como as tradições bantu, que, embora façam parte da história do país, são vinculadas, diversas vezes, à condição de práticas ritualísticas, relegadas a um lugar de menor importância se comparadas às tradições de matriz judaico-cristã. ${ }^{9}$ É, ainda, em virtude de questões como essa, relacionadas a sua vivência em um círculo literário formado, majoritariamente, por homens, que Paulina Chiziane se afastou de Maputo e foi trabalhar na Zambézia (COUTO, 2010).

Assim, é do ponto de vista do tecer estórias que permitam refletir criticamente sobre a realidade moçambicana e ter contato com a memória histórica do país, que podemos tomar a obra $O$ alegre canto da perdiz, resultado dessa vivência. Uma das preocupações presentes, nessa lógica, são os reflexos decorrentes do processo de colonização empreendido pelos portugueses:

\footnotetext{
$8 \quad$ Frantz Fanon (1925-1961), em uma passagem de Peles negras, máscaras brancas, faz uma observação que vem ao encontro da colocada: “[...] A escravidão? Não se falava mais disso, era uma lembrança ruim. [...]” (FANON, 2008, p. 107). Nesse viés, o colonialismo também pode ser tratado como uma lembrança ruim, que se quer ver posta sob o tapete de uma concepção de progresso vinculada à exclusão.

9 Em Ngoma Yethu, Chiziane e Martins (2018) tecem uma crítica nesse sentido, inclusive apontando que, mesmo após a independência, continuou havendo repreensões quanto aos saberes tradicionais (CHIZIANE; MARTINS, 2018, p. 38)
} 
Os marinheiros civilizavam o povo arrancando-lhes os olhos da cara. Cristianizavam fornicando as mulheres nas matas. Construíram o novo mundo com espadas, canhões e chicote. Pacificaram a terra arrancando a língua da boca. O chefe dos marinheiros gritava aos quatro ventos: esse é ladrão, prendam-no. Esse é forte, acorrentem-no, vendam-no. Esse é teimoso, matem-no. Esses são venenosos, são lúcidos, pensam, conspiram, alcoolizem-nos. São todos vaidosos, preguiçosos, vadios, mentirosos, escravizem-nos. (CHIZIANE, 2008, p. 70)

Nessa perspectiva, nos situamos em um período de que emerge um projeto civilizacional que, como bem registra Mudimbe (2013), está em uma estrutura colonizadora que abarca aspectos físicos, humanos e espirituais das experiências durante o período de domínio colonial. Considerando esse processo, constantemente estão presentes, nos personagens, os embates psicológicos entre o local e o global $^{10}$, entre ceder e não ceder, provindos desde a época da colonização portuguesa, passando pela luta pela independência e chegando até a Guerra Civil, que assolou o país no pós-independência até o ano de 1992. A passagem abaixo diz respeito a uma reflexão de/sobre José dos Montes, personagem do romance, homem negro - primeiro marido de Delfina e o pai preto de Maria das Dores - que aceita se tornar assimilado após pressão da esposa para terem uma vida melhor:

[...] Chegou a sua hora. O exército da traição e da morte ganhou mais um. Que vai eliminar da vida todos os pontos vitais. Vai tornar-se inimigo de si próprio. Olhar para a própria raça como um tormento. Matar homens e proteger o palmar. (CHIZIANE, 2008, p. 122)

O juramento que José precisa fazer para ter esse estatuto, demonstra-nos, clara e dolorosamente, os diferentes teores de violência referidos:

[...] Vamos, jura por tudo que não dirás mais uma palavra nessa língua bárbara. Jura, renuncia, mata tudo, para nasceres outra vez. Mata a tua língua, a tua tribo, a tua crença. Vamos, queima os teus amuletos, os velhos altares e os velhos espíritos pagãos. José faz o juramento perante um oficial de justiça, que mais se parece com um juramento de bandeira. Com pouca cerimônia, diante de um oficial meio embriagado.

— Eu juro - repetia.

— Juras abandonar essas crenças selvagens, a língua atrasada, e a vida bárbara?

- Sim, eu juro.

- Bom rapaz. Agora assina aqui. (CHIZIANE, 2008, p. 117, grifos meus)

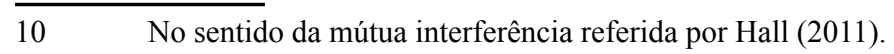


Em um só ato, ele tem de negar a si, à cultura e aos valores com que foi criado. Porém, não na dinâmica de uma negação-aprendizagem que se daria num diálogo com uma ecologia de saberes (SANTOS, 2007), mas por meio do apagamento que decorre de uma submissão imposta por uma colonialidade de saber ${ }^{11}$. Esta, por mais que não gere um apagamento total, implica em uma série de conflitos por que o sujeito tem que passar, no decorrer dos quais passa a considerar-se menor.

Como bem recorda a narradora antes dessa passagem, "colonizar é fechar todas as portas e deixar apenas uma." (CHIZIANE, 2008, p. 117). Dentre as justificativas para se deixar as portas fecharem? "A assimilação era o único caminho para a sobrevivência." (CHIZIANE, 2008, p. 117). Mas que sobrevivência? José dos Montes nunca ficará contente com sua escolha - "No dia em que José segurou a primeira espingarda, chorou. [...] Eu não queria esta arma, nem este punhal. Nem esta farda ridícula de cidadão de segunda classe.” (CHIZIANE, 2008, p. 121). Delfina, por sua vez, não encontra correspondência nos pensamentos de José - "Perdias tempo com ideias de resistência, querendo afirmar uma identidade perdida. Uma dignidade de fome. De escravatura. De morte." (CHIZIANE, 2008, p. 121).

Visualizamos, assim, que o processo de assimilação reverbera de maneira distinta para os personagens e que embora tenha para eles, como eixo norteador, o desejo de aproximação com o modelo europeu de vida, está, por outro lado, percorrido pela ideia de que aos povos africanos faltava o aspecto da civilização. Esse processo, inicialmente pensado em termos de uma inclusão no direito europeu, que, na verdade, não chegou a acontecer ${ }^{12}$, posteriormente se conectou às necessidades do capitalismo por mão de obra. Nesse sentido, “os colonizados deixavam de ser 'iguais' para ser 'tendencialmente' passíveis de se tornarem iguais" (CABAÇO, 2007, p. 146, grifos do autor), questão essa que virá a se refletir na hierarquização de postos de trabalho, que serão ocupados de forma diferenciada por indígenas, não indígenas e assimilados.

A hierarquização aí presente é bastante elucidada por Paulina Chiziane ao trazer a questão da miscigenação racial à cena, colocando as implicações disso para o imaginário e para a realidade social de Moçambique como um todo, uma vez que isso tem reflexos na construção da ideia de nacionalidade moçambicana, no projeto de país que fora pensado na época da independência. Essa construção hierarquizante consiste não apenas em uma óbvia divisão racial entre brancos, negros e mestiços, mas também - e sobretudo - na subalternização do corpo negro, na negação de uma possibilidade de habitar o mundo, como transparece em uma das falas da personagem Delfina: "Os filhos negros representam o mundo antigo. O conhecido. São o meu passado e o meu presente. Sou eu. E eu já não quero ser 11 "[...] o posicionamento do eurocentrismo como ordem exclusiva da razão, conhecimento e pensamento, a que descarta e desqualifica a existência e viabilidade de outras racionalidades epistêmicas e outros conhecimentos que não sejam de homens brancos europeus ou europeizados" (WALSH, 2012, p. 67, tradução minha).

12 "[...] a assimilação em momento algum representou a integração do colonizado como membro da comunidade portuguesa na colónia." (CABAÇO, 2007, p. 162, grifo do autor) 
eu.” (CHIZIANE, 2008, p. 230). Os filhos mestiços, por sua vez, representam o futuro, uma vez que estão relacionados a mecanismos de ascensão social. Conforme Serafina, mãe de Delfina, eles "nunca são presos ou maltratados, são livres, andam à solta. Um dia também serão patrões e ocuparão o lugar dos pais [...]. Felizes as mulheres que geram filhos de peles claras porque jamais serão deportados." (CHIZIANE, 2008, p. 97). Verifica-se, assim, uma ausência de esperança no que se refere a um bom futuro para os filhos negros e uma expectativa quanto ao futuro dos filhos mestiços. De uma forma ou de outra, o posicionamento de Delfina implica o desmerecimento que a pessoa colonizada passa a conferir, nesse caso, à sua própria cor e às suas possibilidades de ação no mundo:

Ao não se considerar como um cidadão, o colonizado também perde a esperança de ver seu filho tornar-se um. Como logo renuncia à ideia para si mesmo, não elabora mais o projeto, eliminando-o de suas ambições paternas e não lhe dando nenhum lugar em sua pedagogia. Nada, portanto, sugerirá ao jovem colonizado a segurança, o orgulho de sua cidadania. Ele não esperará suas vantagens, nem será preparado para assumir seus encargos. (MEMMI, 2007, p. 138)

Delfina tem quatro filhos, sendo as duas meninas as que mais aparecem na narrativa: Maria das Dores, a filha negra, com José dos Montes, e Maria Jacinta, a filha mestiça, com o branco Soares. É aquela que nos recebe no início da obra, ocupando seu espaço em um contínuo que começa em Serafina, a avó, e passa por Delfina, a mãe, formando três gerações de mulheres negras cujas vidas são marcadas pela constante necessidade de reconfiguração de si mesmas:

O colonialismo incubou e cresceu vigorosamente. Invadiu os espaços mais secretos e corrói todos os alicerces. Já não precisa de chicote nem da espada, e hoje se veste de cruz e silêncio. Impregnou-se na pele e nos cabelos das mulheres, assíduas procuradoras da clareza epidérmica, na imitação de uma raça. As bocas das mães negras expelem raivas contra o destino e perdem a melhor energia na fútil reprodução de um deus perfeito. Trinta anos de independência e as coisas voltam para trás. Os filhos dos assimilados ressurgem violentos e ostentam ao mundo o orgulho da sua casta. O colonialismo já não é estrangeiro, tornou-se negro, mudou de sexo e tornou-se mulher. Vive no útero das mulheres, nas trompas das mulheres e o sexo delas se transformou em ratoeira para o homem branco. (CHIZIANE, 2008, p. 226)

Os filhos são diversos e ao corpo negro de Maria das Dores coube a herança da mãe, figurada na entrega de seu corpo para Simba. À Maria Jacinta sucedeu o casamento firmado com um branco. Delfina, de sua parte, não se envergonha de estar no grupo das que vendem seus corpos para conseguir o ganha-pão, ou ao menos não deixa isso defini-la, nem mesmo os sofrimentos por que passa - "Cada homem que me sobe é uma pá de terra que me cobre. Cada moeda que recebo é uma picada 
na alma, dói." (CHIZIANE, 2008, p. 81). Ela acaba culpabilizando a mãe, por tê-la iniciado cedo em sua vida sexual; o pai, por ter recusado à assimilação; José, que não tinha o suficiente para lhe oferecer; Soares, que a elevou e depois abandonou; a ela mesma, por ter desejado o que não poderia ter; o mundo, por tê-la ensinado a odiar (CHIZIANE, 2008, p. 44). As decisões dos pais a impediram de estudar para ser professora, tal qual um dia sonhara. Mas seus conflitos internos não fixam quem ela é, de modo que não há homogeneidade nos pensamentos e decisões dela ou dos demais personagens. ${ }^{13}$

Cabe destacar que a participação do corpo feminino nesse processo de colonização não aparece de forma a culpabilizar a mulher negra nesse processo, mas sim de modo a destrinchar o que, na estrutura colonial, acabou por suscitar isso, tanto para a mulher quanto para o homem negros. Considerando que as mulheres citadas pertencem a gerações distintas (passando pela independência e pela Guerra Civil), as ideias, os questionamentos e aquilo que se aceita como verdade acaba por ser distinto em cada uma delas, o que contribui para realçar os diferentes perfis do feminino trabalhados pela autora, bem como as características que acabam por perpassar as três gerações.

Outro aspecto explorado na obra, nesse contato entre moçambicanos e portugueses, diz respeito ao relacionamento das pessoas com os valores locais e os valores coloniais, o que igualmente pode ser vinculado ao status que a cor e a cultura vinculada a determinada cor evocam culturalmente para as pessoas. Por exemplo, não há concordância sobre o nome a ser dado à primeira filha de Delfina e José dos Montes:

[...] - Se for mulher, terá o nome da minha mãe - diz José dos Montes. — Nome da tua mãe? Não. Somos agora assimilados, e vivemos a vida dos brancos. Juraste abandonar as tradições cafres, esqueceste? (CHIZIANE, 2008, p. 413).

Além disso, Delfina, após o nascimento de Maria das Dores, se nega a tomar os chás oferecidos pela mãe, preferindo os antibióticos que o marido trouxera da farmácia. Por outro lado, no decorrer da trama, será um curandeiro, o mesmo Simba a quem entregou Maria das Dores, que ela procurará para ter o amor de um homem branco, não alguma figura simbólica da tradição europeia. Podemos visualizar, em momentos como esse, os conflitos que percorrem as relações sociais em um espaço no qual aquilo que está relacionado às culturas locais é tratado como inferior ao que foi trazido pela colonização europeia, pelo colonizador branco.

Nesse sentido, é interessante evocarmos Lugones (2014), que, ao discutir sobre a chamada "missão civilizatória" do ocidente, considera-a enquanto "máscara eufemística do acesso brutal aos

13 Até mesmo Soares, o homem branco. Ele fica com a amante negra (Delfina), não admite para os colegas de trabalho que Maria Jacinta é sua filha e, ao mesmo tempo, repreende Delfina por ela tratar de forma diferente as crianças, devido à cor. 
corpos das pessoas através de uma exploração inimaginável, violação sexual, controle da reprodução e terror sistemático" (LUGONES, 2014, p. 938), sob a justificativa da transformação civilizatória. Transformação esta que, conforme pudemos ver nos breves trechos citados, gera todo um processo de diferenciação racial e cultural que influenciou não apenas na formação do que Moçambique é hoje, mas também na de todo o planeta, tendo em vista que essa é uma ideia engendrada nos processos colonizatórios como um todo.

\section{Considerações finais}

Em meio às breves leituras aqui traçadas, que passam por violências epistêmicas, psíquicas, corporais e físicas, pode ser visualizada uma série de contextos formativos que encontram aporte na realidade dos corpos negros e no corpo negro feminino, bem como no mestiço, durante o processo de colonização. O trabalho com esses contextos, por sua vez, está em constante diálogo com reflexões feitas por estudos como os culturais, de gênero e de raça na medida em que todos trazem, entre seus desafios, o de registrar e discutir sobre as histórias não contadas, de um ponto de vista que não o do colonizador ou ocidental.

Paulina Chiziane figura, pois, em sua singularidade, nesse grupo de luta política que considera as vozes e tradições locais - inclusive por ser, ela mesma, uma dessas vozes - nesse constante embate formativo que foi (e é) o contato entre os diferentes grupos culturais que fazem parte da formação de Moçambique. Cada voz na narrativa, seja em referência ao período de regime colonial direto, trabalhado nesse ensaio, seja em relação com o período pós-independência, de sonho, de luta e de questionamento das heranças deixadas pelo período colonial, nos permite esse encontro poético e vivo entrecortado pela busca de discussão dos embates resultantes do colonialismo, desde o período colonial propriamente dito até o momento atual.

Prosseguindo nessa perspectiva, interessante evocar Mignolo (2008), que, ao discutir sobre desobediência epistêmica, pondera acerca da importância de estarmos atentos para o pensar por meio de línguas e categorias de pensamento exteriores àquelas que fazem parte da história do pensamento ocidental (MIGNOLO, 2008, p. 305). Podemos incluir a escrita de Paulina Chiziane nesse contexto na medida em que ela, embora escreva em língua portuguesa, não a tem como língua materna ${ }^{14}$, o que traz implicações para seu estilo de escrita ${ }^{15}$. Junto a esse trabalho narrativo, a autora se preocupa

14 Paulina menciona, em entrevista, que sua língua materna é o chope, mas que também fala um pouco de ronga e changana. Acerca da língua portuguesa, ela a aprendeu na escola, sendo que não era uma língua que podia ser utilizada em casa. (CHIZIANE, 2018)

15 Implicações essas que dizem respeito a aspectos como o português moçambicano, a apropriação de uma segunda língua e o diálogo com formas de narrar africanas, nesse caso relacionadas às tradições bantu, e com as formas europeias, pontos de discussão que estão sendo aprofun- 
em pensar a sociedade moçambicana considerando conhecimentos que pessoas no país têm, mas não podem registrar por não escreverem. Ou, ainda, em trazer problemas por que a sociedade moçambicana passa, porém, que não são tratados com o devido cuidado pelas autoridades que administram o país. Dessa maneira, obras como $O$ alegre canto da perdiz permitem que a atenção dos leitores seja direcionada para essas questões por meio de um olhar que se direciona, de dentro do país, para os reflexos que a miscigenação e a diferenciação racial têm na concepção do moçambicano sobre si e sua própria história, de forma a rever a maneira como elas, nutridas pelo processo de colonização, afetam o seu habitar o mundo.

\section{Referências}

CABAÇO, José L. de O. Moçambique: identidades, colonialismo, libertação. 2007. 474 f. Tese (Doutorado) - Curso de Antropologia Social, Departamento de Antropologia, Universidade de São Paulo, São Paulo, 2007.

CHIZIANE, Paulina. Guerras, mulheres e memórias: entrevista com a escritora Paulina Chiziane. [Entrevista concedida a] Tiago Ribeiro dos Santos. Revistas Estudos Feministas, Florianópolis, v. 26, n. 2, 2018. Disponível em: https:// periodicos.ufsc.br/index.php/ref/article/view/45904/37107. Acesso em: 15 nov. 2018.

CHIZIANE, Paulina. Não volto a escrever. Basta. [Entrevista concedida a] José Maria Remédios. In: PORTAL Geledés, 11 de julho de 2016. Disponível em: https://www.geledes.org.br/paulina-chiziane-nao-volto-escrever-basta/. Acesso em: 07 mar. 2019.

CHIZIANE, Paulina; MARTINS, Mariana. Ngoma Yethu: o curandeiro e o Novo Testamento. Belo Horizonte: Nandyala, 2018.

CHIZIANE, Paulina. O alegre canto da perdiz. Lisboa: Caminho, 2008.

CHIZIANE, Paulina. Os anjos de Deus são brancos até hoje. [Entrevista concedida a] Doris Wieser. Revista Buala (on-line), 26 de novembro de 2014. Disponível em: http://www.buala.org/pt/cara-a-cara/os-anjos-de-deus-sao-brancos-ate-hoje-entrevista-a-paulina-chiziane. Acesso em: 07 mar. 2019.

COUTO, Mia. Mia Couto: narrar o lado menos bonito e que também não é falado também é parte do ofício do escritor. [Entrevista cedida a] Rosália Estelita Gregório Diogo. Scripta, Belo Horizonte, v. 14, n. 27, p. 195-205, $2^{\circ}$ sem. 2010. Disponível em: http://ibict.pucminas.br/index.php/scripta/article/view/4341/4488. Acesso em: 07 mar. 2019.

FANON, Frantz. A experiência vivida do negro. In: . Pele negra, máscaras brancas. Trad. Renato de Silveira. EDUFBA: Salvador, 2008, p. 103-126.

dados na dissertação a que este artigo se vincula. 
HALL, Stuart. A identidade cultural na pós-modernidade. Trad. Tomaz Tadeu da Silva. 11. ed. Rio de Janeiro, DP\&A, 2011.

HUYSSEN, Andreas. Mapeando o pós-moderno (1984). Trad. Carlos A. de C. Moreno. In: HOLANDA, Heloísa Buarque de. Pós-modernismo e política. 3. ed. Rio de Janeiro: Rocco, 1992, p. 15-80.

LUGONES, María. Rumo a um feminismo descolonial. Trad. Juliano Watson e Tatiana Nascimento. Estudos Feministas, Florianópolis, n. 22, p. 935-952, set.-dez. 2014. Disponível em: https://periodicos.ufsc.br/index.php/ref/article/ view/36755. Acesso em: 07 mar. 2019.

MARCELINO, Jaqueline L. L. Mulheres negras: tradições orais, artes, ofícios e identidades. 2016. 230 f. Tese (Doutorado) - Programa de Pós-graduação em Letras, Centro de Ciências Humanas e Naturais, Universidade Federal do Espírito Santo, Vitória, 2016. Disponível em: http://repositorio.ufes.br/handle/10/9174. Acesso em: 03 ago. 2019.

MATTOS, Regiane A. de. A dinâmica das relações no Norte de Moçambique no final do século XIX e início do século XX. Revista de História, São Paulo, n. 171, p. 383-419, dez. 2014. Disponível em: http://www.scielo.br/scielo.php?script=sci_arttext\&pid=S0034-83092014000200383. Acesso em: 19 ago. 2019.

MEMMI, Albert. Retrato do colonizado precedido de retrato do colonizador. Trad. Marcelo Jacques de Moraes. Rio de Janeiro: Civilização Brasileira, 2007.

MIGNOLO, Walter D. Desobediência epistêmica: a opção descolonial e o significado de identidade em política. Trad. Ângela Lopes Norte. Cadernos de Letras da UFF, dossiê Literatura, língua e identidade, Niterói, n. 34, p. 287-234, 2008. Disponível em: http://www.cadernosdeletras.uff.br/joomla/images/stories/edicoes/34/traducao.pdf. Acesso em: 07 mar. 2019.

MUDIMBE, V. Y. A invenção da África. Gnose, Filosofia e a Ordem do Conhecimento. Odivelas: Pedago; Luanda: Mulemba, 2013.

PINTO, Maria J. P. R. B. Estado, poderes linhageiros, poderes religiosos muçulmanos nos macuas de Nacala: oposições, ambiguidades e convergências. 2015. 321 f. Tese (Doutorado) - Escola de Sociologia e Políticas Públicas, Departamento de Ciência Política e Políticas Públicas, Instituto Universitário de Lisboa, Lisboa, 2015. Disponível em: https://repositorio.iscte-iul.pt/handle/10071/11391. Acesso em: 03 ago. 2019.

SAID, Edward W. Orientalismo: o Oriente como invenção do Ocidente. Tradução Tomás Rosa Bueno. São Paulo: Companhia das Letras, 1990.

SANTOS, Boaventura de S. Para além do pensamento abissal: das linhas globais a uma ecologia de saberes. Novos estudos, CEBRAP, São Paulo, no 79, p. 71-94, nov. 2007. Disponível em: http://www.scielo.br/scielo.php?script=sci_arttext\&pid=S0101-33002007000300004. Acesso em: 07 mar. 2019.

WALSH, Catherine. Interculturalidad e (de)colonialidad: perspectivas críticas e políticas. Visão Global, Joaçaba, vol. 15, n. 1-2, p. 61-74, jan.-dez. 2012. Disponível em: https://portalperiodicos.unoesc.edu.br/visaoglobal/article/ view/3412. Acesso em: 29 mar. 2019. 